\title{
O ALUNO E O DESINTERESSE EM APRENDER: PERCEPÇÕES E INTERPRETAÇÕES DE PROFESSORES DO ENSINO FUNDAMENTAL II
}

Izabella Alvarenga Silva, Taislene Guimarães, Luciana Aparecida Nogueira da Cruz, Raul Aragão Martins.

Universidade Estadual Paulista - UNESP, Doutorado em Educação, Presidente Prudente, SP. E-mail: izabella.silva@gmail.com. Agência de fomento: Capes

\section{RESUMO}

Questões de diferentes naturezas tem afetado o trabalho de professores em todo o país, e o desinteresse dos alunos em aprender é uma queixa comum no relato destes profissionais, especialmente daqueles que trabalham no ensino público. Posto isso, estabelecemos como objetivo apresentar algumas considerações sobre como professores do ensino fundamental II percebem e interpretam o desinteresse dos seus alunos em aprender. Para tanto, duas questões foram aplicadas em vinte e quatro professores e analisadas por meio de eixos temáticos e categorias de repostas. Os eixos relataram como os docentes percebem a manifestação do desinteresse dos alunos em aprender e suas interpretações do porquê apresentariam tal postura. Os resultados, encontramos neste grupo de sujeitos participantes foram ao encontro da atribuição de uma relativa responsabilização pessoal do aluno e ao mesmo tempo uma não visão do próprio educador como autor e, portanto, também responsável pelo resultado do processo.

Palavras-chave: professor, percepção, desinteresse, aprendizagem, alunos.

\section{THE STUDENT AND THE LACK OF INTEREST IN LEARNING: PERCEPTIONS AND INTERPRETATIONS FROM TEACHERS OF THE SECOND YEAR OF ELEMENTARY SCHOOL}

\begin{abstract}
Issues of different natures is affecting the work of teachers all over the country, and the lack of interest in learning on students is a common complaint in these professionals reports, specially thos who work in public education. With that said, we set as our goal to present a few considerations about how teacher of the second year of elementary school perceives and interprets the lack of interest in learning of their students. Therefore, it was applied two questions at 24 teachers and analyzed by thematic axes and answer categories. The axes reported how the teachers perceive the manifestation of the lack of interest in learning and their interpretations of why they present such posture. The results we found in this group of participating subjects agree on the assignment of a relative personal accountability of the student and, at the same time, they do not see themselves as authors, therefore, also accountable for the process result.
\end{abstract}

Keywords: teacher, perception, lack of interest, learning, students. 


\section{INTRODUÇÃO}

Atualmente, há estudos apontando a dificuldade encontrada pelo professor em dar continuidade a sua carreira, devido a diversos fatores como a pouca valorização profissional, condições precárias de trabalho e problemas como a indisciplina e desinteresse dos alunos (JESUS, 2004; SOUTO, 2016; REIS, 2012; FRANKIV, DOMINGUES,2016).

Somados a estes resultados, acreditamos que a política pública na área da Educação, a precária infraestrutura das unidades escolares, a estagnação dos planos de carreira e o cotidiano exaustivo da sala de aula também têm feito professores do todo o país, especialmente aqueles do ensino público, repensarem seus projetos futuros na profissão.

Diante destes, a relação entre professor e aluno tem se mostrado conflituosa, caótica e muitas vezes de difícil entendimento para ambos os lados. Os professores fazem constantes queixas sobre comportamento opositor dos alunos, que por vezes apresenta caráter de vandalismo, violência, intimidação e recusa da realização de atividades como tarefas, trabalhos e exercícios.

Até a década de 1950, o Brasil era um país essencialmente rural. A partir da década de 1960, com o crescimento dos grandes centros urbanos e com a expansão do segmento industrial, a escola tem atendido um número cada vez maior de alunos, servindo para a aprendizagem dos conhecimentos básicos e capacitação para o mundo do trabalho. No entanto, a expansão no atendimento à população não foi acompanhada pela expansão da qualidade do serviço oferecido.

O progresso tecnológico alcançado nos últimos tempos pela ciência tem exigido que a formação intelectual do homem seja mais profunda e especifica. No entanto, o período pósmoderno vivido hoje evidencia que a relação do homem com a política, com a economia, com a tecnologia, com a ciência e com o grupo do qual fazemos parte está essencialmente marcada pela incerteza, a efemeridade, a mobilidade, a flexibilidade, a fragmentação, a imprevisibilidade e o imediatismo, além da inversão de valores, da apatia, do espetáculo e do prazer sem frustração. (BAUMAN, 2001)

Diante deste cenário nos questionamos: A escola, o professor e o aluno têm acompanhado tais transformações?

Se tomarmos como referência o último século, a escola enquanto instituição pouco mudou. Como nos lembra Foucault (1999) o caráter centralizador, normatizador e de aprisionamento de liberdade e ideias ainda se mantém, e neste contexto, o professor ainda é a figura responsável por organizar e socializar todas as informações que ali circulam; cenário que, a nosso ver, não mais da conta das necessidades emergentes da atualidade e que contribui para que aumentem a dificuldade de alunos e professores compartilharem o elemento que os une, o conhecimento.

Neste cenário, surge uma questão: tal desinteresse dos alunos é real? Uma pesquisa apresentada pelo jornal $\mathrm{O}$ estado de São Paulo ${ }^{1}$ aponta que o elevado número de faltas dos estudantes do ensino médio à escola relaciona-se, entre outros fatores, com o desinteresse destes. E como os tempos atuais são tempos de consumo, e tudo que foge disso torna-se pouco atrativo. Oliveira e Tomazetti (2012) tecem considerações interessantes sobre a condição dos jovens de estarem imersos em uma sociedade que organiza-se através do consumo:

Ver a vida escolar, pois, como um empreendimento, tal como um processo paulatinamente desenvolvido ao longo de alguns anos, dotada de um sentido interligado com as demandas particulares de cada sujeito e que culminará com a assunção de atributos pessoais respeitáveis e meritórios, tem se mostrado uma construção de sentido escasso, senão ausente, para inúmeros adolescentes e jovens. Estar no Ensino Médio, de outra forma, mostra-se cada vez mais uma experiência sem qualquer sentido, salvo o

\footnotetext{
${ }^{1}$ http://www.estadao.com.br/noticias/geral,desinteresse-dos-alunos-do-ensino-medio-e-2-principal-motivo-de-faltas-imp-,575665
} 
imperativo do diploma desta etapa do ensino para o ingresso em escassas oportunidades do mercado de trabalho ou a conclusão de um período indispensável para se ingressar em um curso superior [...]. Encontrar-se na sala de aula, desse modo, torna-se algo notadamente enfadonho, desinteressante e entediante para aqueles jovens cidadãos consumidores acostumados a aguardarem apenas segundos, após digitarem as senhas de seus cartões de crédito, para verem satisfeitos seus desejos. (OLIVEIRA, TOMAZETTI, p. 190, 2012).

Nesse sentido, o desinteresse dos alunos em relação à escola e aos processos de ensino e aprendizagem ali encaminhados é objeto de questionamento de pais, professores, gestores e estudiosos da área. Após constantes afirmações destes sobre a recusa, desinteresse e falta de motivação dos alunos em aprender, nos debruçamos sobre tal questão.

Assim, o objetivo que traçamos para este texto é apresentar algumas considerações sobre como professores do ensino fundamental avaliam o desinteresse dos seus alunos em aprender. Não almejamos esgotar o tema, e sim compreender como esta questão tem sido pensada por aqueles que a vivem diariamente.

\section{METODOLOGIA}

Os dados apresentados são decorrentes de uma pesquisa realizada entre os anos de 2015 e 2016 em uma escola pública de ensino fundamental, localizada em uma cidade do interior paulista. No ano de 2015, esta escola matriculou 425 alunos no sexto ao nono ano, o quadro de funcionários estava composto por vinte e nove docentes, a maioria concursados, três gestoras (diretora, vice-diretora e coordenadora pedagógica), além de auxiliares administrativos e profissionais da limpeza. De acordo com Gil (2008), esta pesquisa pode ser caracterizada como de abordagem qualitativa, de natureza aplicada e caráter descritivo.

Os sujeitos participantes foram vinte e quatro professores atuantes nesta instituição, em sua maioria do sexo feminino (58,62\%), graduados em Letras e Matemática principalmente $(34,48 \%)$, com ao menos um curso de pós-graduação $(58,62 \%)$, trabalhavam exclusivamente na escola onde a pesquisa foi realizada (58,33\%), possuíam de 6 a 10 anos de carreira docente $(41,38 \%)$, de religião católica $(48,28 \%)$ e na classificação socioeconômica estavam no nível $B$ (71,51\%), de acordo com o Critério Brasil.

Estes professores participaram de uma atividade formativa com duração de quatorze meses, entre os anos de 2015 e 2016. Dos muitos momentos vividos ao longo deste processo formativo, selecionamos e analisamos neste texto apenas as concepções destes profissionais sobre o desinteresse dos seus alunos em aprender, as quais puderam ser conhecidas mediante duas questões aplicadas em forma de questionário: São elas: a) como você percebe o desinteresse dos alunos? e b) por que os alunos estão desinteressados em aprender os conteúdos curriculares?. As respostas dadas a estas questões foram analisadas qualitativamente segundo a técnica de análise de conteúdo proposta por Bardin (1979).

Esta investigação foi submetida a um Comitê de Ética em Pesquisa e recebeu parecer favorável (CAAE: 38224914.6.0000.5406).

\section{RESULTADOS}

Inicialmente realizamos uma leitura atenta e minuciosa do material, exploramo-los na busca de sentidos mais amplos, ideias implícitas e diálogo com outros estudos e, por fim, criamos uma síntese interpretativa, a qual pode ser apresentada diante de dois grandes eixos temáticos: Percepção e Interpretação. 
Eixo temático I - Percepção

Decorrente da aplicação do questionamento Como você percebe o desinteresse dos alunos?, foram encontradas duas categorias de respostas:

Categoria 1 - Não realização de atividades propostas

Esta categoria, presente da maioria dos discursos, foi constituída por respostas que remetem a percepção do desinteresse dos alunos à realização ou não de atividades propostas pelo docente. Vejamos um exemplo:

O aluno não faz a tarefa proposta. Não acompanha as explicações do conteúdo. Muitas vezes copia as respostas dos colegas somente como obrigação. $\left(\operatorname{Mar}^{* *}\right)^{2}$

Quase todo o grupo que respondeu à este questionamento acredita que os alunos demonstram o desinteresse em aprender quando recusam-se a fazer as atividades solicitadas pelos professores de diferentes disciplinas.

Categoria 2 - Comportamentos inadequados

Além da não realização de tarefas e atividades, os professores relataram que percebem o desinteresse dos alunos em aprender também diante do comportamento apresentado em sala de aula como pontua Var**: Pelas atitudes deles: bagunça. Ou ainda $\mathrm{Na}^{* *}$ :

Pelas atitudes de indisciplina que eles apresentam em sala de aula. Falta de atenção na hora das explicações. Não tem vontade na realização de atividades e tarefas.

Para os professores, a bagunça, ou desordem, na sala de aula é uma espécie de termômetro para medir interesse da turma. Dessa forma, se a turma é desordeira, logo é desinteressada, e se a turma é quieta e ordenada, há interesse nos conteúdos curriculares.

Eixo temático II - Interpretação

Diante do questionamento por que os alunos estão desinteressados em aprender os conteúdos curriculares? os docentes se posicionaram e suas hipóteses para esta postura desinteressada dos alunos puderam ser classificadas em três categorias.

Categoria 1 - Pouca utilidade e/ou aplicabilidade dos conteúdos no cotidiano

Boa parte do grupo, configurando a maioria dos sujeitos da pesquisa, apontou como explicação para o 'não querer aprender' dos alunos configuração atual dos conteúdos oferecidos. Seguem exemplos:

Na disciplina de matemática, os conteúdos estão fora da atual realidade. Alguns conteúdos não dão para trazer para o cotidiano e sempre ouço "onde vou usar isso?". (Pau**)

Porque na maioria das vezes eles não conseguem enxergar onde vão utilizar os conteúdos em suas vidas cotidianas. E também porque desde muito pequenos já tem acesso a diversas informações e acham que não necessitam de nenhuma formação. (Alc**)

Categoria 2 - Interesse exclusivo por tecnologia

Em menor número estão os sujeitos que citaram a tendência dos jovens em interessaremse apenas por tecnologia como ressalta Reg**: Porque estamos na era tecnológica, onde tudo se resolve em um clik, muito rápido e imediatista.

\footnotetext{
${ }^{2}$ Para preservar a identidade dos sujeitos da pesquisa, adotamos esta identificação para os mesmos. 
Categoria 3 - Falha na educação dada pelas famílias

E houve também aqueles que apontaram falhas na educação fornecida pela família, em casa:

Não há há incentivo da família. (Lu**)

Acredito que para nossos alunos é a imaturidade aliado ao seio familiar (falta de cobrança). (Gab **)

Em seguida buscaremos tecer alguns comentários diante dos dados apresentados.

\section{DISCUSSÃO}

Em suma, exame destes dados nos permitiu identificar um fator de responsabilização pessoal dos alunos pela postura desinteressada que apresentam diante das disciplinas escolares. Além disso, foi possível notar, a partir de uma análise mais profunda do material, que os professores apontaram sempre um fator externo à escola, e a sua própria participação, para explicar tal desinteresse.

Exemplos como a dificuldade da escola enquanto instituição, e dos próprios docentes enquanto profissionais, no planejamento e proposição de aulas, atividades, projetos e avaliações diferenciadas não foi citada. Estes dois pontos nos fizeram concluir que, para estes professores, existe uma questão urgente que é a falta de interesse dos alunos em aprender, e a responsabilidade por tal questão está fora da escola, está no aluno que não vê aplicabilidade dos conteúdos.

As falas dos professores, apresentadas anteriormente, apontam ainda para uma falta de um exame mais crítico do contexto atual, para a superação da culpabilização pessoal dos alunos em relação ao desinteresse pela escola. Mais evidente no ensino médio, tal postura do alunado é indicativo de que diferentes aspectos relacionam-se e constituem a relação sociedade e escola, hoje marcada pelo viés consumista apontado por Bauman (2001).

A relação do aluno com a escola se insere em um contexto mais amplo que não pode ser ignorado, e a falta de aplicabilidade dos conteúdos, argumento apresentado pelos sujeitos desta pesquisa, é sintomático de uma relação que não vai bem.

\section{CONSIDERAÇÕES FINAIS}

Como considerações (nada) finais, temos que o desinteresse dos alunos em aprender está presente nos relatos de professores e parece ser uma constante nas salas de aula, especialmente as do ensino público. A precária infraestrutura das escolas, a estagnação na carreira e a dificuldade em lidar com questões como esta têm feito professores questionarem sua permanência neste segmento de trabalho.

Para os sujeitos desta pesquisa, os alunos estão desinteressados em aprender porque, principalmente, não enxergam aplicabilidade do conteúdo trabalhado em sala de aula, e demonstram isso na recusa em realizar atividades como tarefas, trabalhos e exercícios. No bojo destas questões, entendemos que há uma relativa responsabilização pessoal do aluno no referido desinteresse e, ao mesmo tempo, uma dificuldade do professor em se colocar como agente do processo.

\section{REFERÊNCIAS}

BARDIN, L. Análise de conteúdo. Lisboa: Edições 70, 1979.

BAUMAN, Z. Modernidade Líquida. Tradução: Plínio Dentzien. Rio de Janeiro: Jorge Zahar Ed., 2001. 
FOUCAULT, M. Vigiar e punir. Nascimento da prisão. Petrópolis: Editora Vozes, 1999.

FRANKIV, M. A.; DOMINGUES, S. C. Desinteresse e proposições para escola atual: contribuições do pensamento complexo. Revista Tempos e Espaços em Educação, São Cristóvão, v. 9, n. 19, p. 113$128,2016$.

GIL, A. C. Métodos e técnicas de pesquisa social. 6. ed. São Paulo: Atlas, 2008.

JESUS, S. N. Desmotivação e crise de identidade na profissão docente. Revista Katálysis, Florianópolis, v. 7, n. 2, p. 192-202, 2004.

OLIVEIRA, A. M.; TOMAZETTI, E. M. Quando a sociedade de consumidores vai à escola: um ensaio sobre a condição juvenil no ensino médio. Educar em Revista, Curitiba, n. 44, p. 181-200, 2012.

REIS, R. R. A escola e a produção do desinteresse. In: XVI ENDIPE - ENCONTRO NACIONAL DE DIDÁTICA E PRÁTICAS DE ENSINO, 2012, Universidade de Campinas, Campinas. Anais ... Campinas, 2012, p. 10-20.

SOUTO, R. M. A. Egressos da licenciatura em matemática abandonam o magistério: reflexões sobre profissão e condição docente. Educação e Pesquisa, São Paulo, v. 42, n. 4, p. 1077-1092, 2016, https://doi.org/10.1590/s1517-9702201608144401.

SZYMANSKI, M. L. S.; PEZZINI, C. C. O novo desafio dos educadores: como enfrentar a falta de desejo de aprender? In: SIMPÓSIO DE EDUCAÇÃO FORMAÇÃO DE PROFESSORES NO CONTEXTO DA PEDAGOGIA HISTÓRICO-CRÍTICA/XIX SEMANA DE EDUCAÇÃO DO CAMPUS CASCAVEL, 2007, Unioeste, Cascavel. Anais ... Cascavel, 2007. Disponível em:

<http://www.unioeste.br/cursos/cascavel/pedagogia/eventos/2007/trabalhos.html> Acesso em abril de 2017. 